\title{
Stability of an epidural analgesic admixture containing butorphanol tartrate and ropivacaine hydrochloride
}

\author{
Fuchao Chen, ${ }^{1}$ Peng Li, ${ }^{1}$ Benhong Zhou, ${ }^{2,3}$ Baoxia Fang, ${ }^{1}$ Jinguo Yang ${ }^{1}$
}

${ }^{1}$ Department of Pharmacy, Affiliated Dongfeng Hospital, Hubei University of Medicine, Shiyan, Hubei, P.R. China ${ }^{2}$ College of Pharmacy, Wuhan University, Wuhan, Hubei, P.R. China

${ }^{3}$ Department of Pharmacy, Renmin Hospital of Wuhan University, Wuhan, Hubei, P.R. China

\section{Correspondence to} Dr Fuchao Chen, Department of Pharmacy, Affiliated Dongfeng Hospital, Hubei University of Medicine, No 16, Daling Road, Shiyan, Hubei Province 442008, P.R. China; dfyycfc@163.com

Received 1 February 2014 Revised 31 March 2014 Accepted 4 April 2014 Published Online First 28 April 2014

\begin{abstract}
Background Local anaesthetics and opioid mixtures are commonly used for the management of postoperative pain. The purpose of this study was to investigate the stability of butorphanol tartrate and ropivacaine hydrochloride in polyolefin bags over a period of 15 days, both at room temperature and at $4^{\circ} \mathrm{C}$.

Methods Admixtures were assessed initially and for 15 days after preparation in polyolefin bags using $0.9 \%$ sodium chloride injection as diluents and stored at $4^{\circ} \mathrm{C}$ and $25^{\circ} \mathrm{C}$. The initial concentrations were $50 \mu \mathrm{g} / \mathrm{mL}$ butorphanol and $1-2 \mathrm{mg} / \mathrm{mL}$ ropivacaine. The stabilities were determined by visual inspection, $\mathrm{pH}$ measurement and high-pressure liquid chromatography assay of drug concentrations.
\end{abstract}

Results The initial concentrations of butorphanol and ropivacaine were $>97 \%$ after 15 days. The drug mixtures were clear in appearance and no colour change or precipitation was observed. Throughout this period, the $\mathrm{pH}$ value remained stable.

Conclusions Butorphanol and ropivacaine in $0.9 \%$ sodium chloride injection are stable for at least 15 days when stored in polyolefin bags at $4^{\circ} \mathrm{C}$ and $25^{\circ} \mathrm{C}$.

\section{INTRODUCTION}

Combinations of local anaesthetics and opioids are often used in clinical practice for the management of moderately severe postoperative pain by patientcontrolled epidural analgesia (PCEA) to ensure that a minimal dose of each is used. ${ }^{1-3}$ One such drug mixture is a combination of butorphanol and ropivacaine. The structures of the drugs are shown in figure 1.

Butorphanol tartrate (figure 1A), morphinan-3, 14-diol, 17-(cyclobutylmethyl)-, $(-)$-, $\left(S-\left(R^{*}, R^{*}\right)\right)-2$, 3-dihydroxybutanedioate $(1: 1)$ (salt), a synthetic opioid, is a $\mu$-opioid antagonist and a $\kappa$-receptor agonist. ${ }^{4-7}$ The WHO suggests that butorphanol use in humans is as an anaesthetic or pre-anaesthetic adjunct or a narcotic analgesic for postoperative pain. Ropivacaine hydrochloride (figure 1B), (-)-(2S)-N-(2,6-dimethyl phenyl)-1-propylpiperidine2-carboxamide hydrochloride monohydrate, is a long-acting local anaesthetic agent mainly used in surgery and for postoperative pain relief. ${ }^{8}$ Previous studies have shown that epidural butorphanol-ropivacaine combination via a patient-controlled anaesthesia pump provides better analgesia and reduces undesirable side effects. ${ }^{9-13}$ However, there are no commercially available analgesic mixtures and they must be prepared in hospital pharmacy departments for clinical use. Mixing two or more drugs together in infusion solutions can lead to physical or chemical changes, or both, which may result in a variation in the therapeutic properties and unwanted side effects. ${ }^{14}$ To our knowledge, the stability of butorphanol with ropivacaine in infusion solutions has not been reported in the literature. In the current study we determined the stability of butorphanol combined with ropivacaine in $0.9 \%$ sodium chloride stored in polyolefin bags over a period of 15 days at $4^{\circ} \mathrm{C}$ and $25^{\circ} \mathrm{C}$ in order to provide background information on the storage of a butorphanol-ropivacaine mixture.

\section{METHODS}

\section{Materials and reagents}

Butorphanol tartrate and ropivacaine hydrochloride reference standards were obtained from the National Institute for the Control of Pharmaceutical and Biological Products, Beijing, China. Butorphanol tartrate injection $(1 \mathrm{mg} / \mathrm{mL}$, lot 121225) was obtained from Hengrui Medicine Co, Jiangsu, China; ropivacaine hydrochloride injection $(75 \mathrm{mg} / 10 \mathrm{~mL}$, lot 1211015) was supplied by Qilu Pharmaceutical Co, Shangdong, China; and the solution of $0.9 \% \mathrm{NaCl}$ used to prepare the sample mixtures was obtained from Kelun Pharmaceutical Co, Sichuang, China. Acetonitrile was of high-pressure liquid chromatography (HPLC) grade purchased from Fisher Scientific International, St Louis, Missouri, USA. Distilled and deionised water were used throughout the study. Potassium dihydrogen phosphate $\left(\mathrm{KH}_{2} \mathrm{PO}_{4}\right)$ was obtained from Xilong Chemical, Guangdong, China.

\section{Equipment}

A modular Dionex HPLC system equipped with a UltiMate 3000 quaternary gradient pump, ASI-100 autosampler, TCC-100 thermostat column oven, ultraviolet detector (DAD) and a data system (Chromeleon V.6.80) was used. Measurements of $\mathrm{pH}$ were determined with a precision $\mathrm{pH}$ meter (Model pHS-3C, Leici Instrument Co, Shanghai, China).

\section{Chromatographic conditions}

A Hypersil $\mathrm{C}_{18}$ analytical column $250 \times 4.6 \mathrm{~mm}$, $5 \mu \mathrm{m}$ particle size (Thermo Electron, USA) was used as a stationary phase. The mobile phase consisted of $0.05 \mathrm{~mol} / \mathrm{L} \mathrm{KH_{2 }} \mathrm{PO}_{4}$ and acetonitrile in the proportion of $75: 25(\mathrm{v} / \mathrm{v})$ with a flow rate of $1.0 \mathrm{~mL} / \mathrm{min}$. The selected detection wavelengths for butorphanol and ropivacaine were 280 and $263 \mathrm{~nm}$, respectively. The column temperature was kept ambient and injection volume was $20 \mu \mathrm{L}$.

\section{Preparation of stock and working solutions}

Butorphanol tartrate $1.0 \mathrm{mg} / \mathrm{mL}$ and ropivacaine hydrochloride $4.0 \mathrm{mg} / \mathrm{mL}$ stock solutions were 


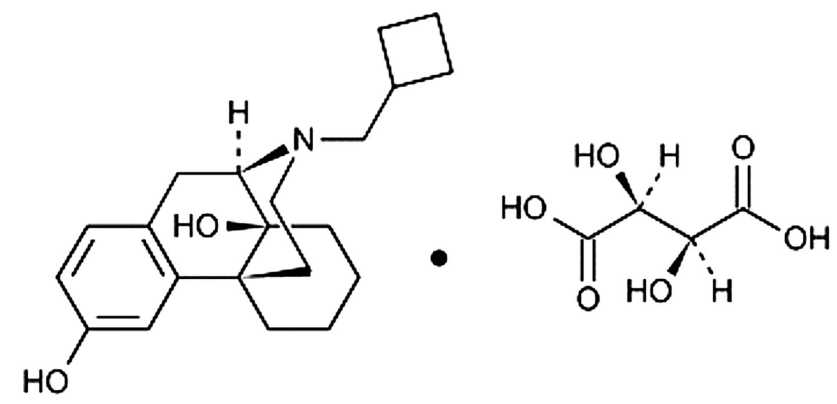<smiles>CCCN1CCCC[C@H]1C(=O)Nc1c(C)cccc1C</smiles>

Figure 1 Structures of (A) butorphanol tartrate and (B) ropivacaine hydrochloride.

prepared in deionised water and frozen at $-20^{\circ} \mathrm{C}$. Fresh working standard solutions were prepared by diluting the stock solution with deionised water to the required concentrations before use.

\section{Method validation}

Validation of the method was made in terms of linearity, accuracy, intra- and inter-day precision and stability indication for each drug.

\section{Linearity}

The calibration curves were established by injecting six concentrations of butorphanol tartrate and ropivacaine hydrochloride in the concentration range $2.5-200.0 \mu \mathrm{g} / \mathrm{mL}$ and $0.1-2.0 \mathrm{mg} /$ $\mathrm{mL}$, respectively. Linear regression was calculated by the peak areas versus concentration of analytes.

\section{Precision and accuracy}

Assays of control solutions at three different concentrations of butorphanol tartrate and ropivacaine hydrochloride were undertaken to calculate the accuracy, intra-day and inter-day precisions. Accuracy and intra-day precision were estimated by means of the recovery value and relative SD (RSD, \%) calculated from three quality control samples with five determinations per concentration at the same day. Inter-day precision (5 days) was also estimated as the RSD calculated from five replicate mixture samples prepared in the same way.

\section{Stability indication}

The stability-indicating capability of the chromatographic method was assessed using partially decomposed solutions of drug. The butorphanol tartrate and ropivacaine hydrochloride mixture degraded by heating at $60^{\circ} \mathrm{C}$ for $5 \mathrm{~h}$ under acidic (0.1 M hydrochloric acid), basic ( $0.1 \mathrm{M}$ sodium hydroxide) and $3 \%$ hydrogen peroxide $\left(\mathrm{H}_{2} \mathrm{O}_{2}\right)$ conditions was assayed to confirm separation of the parent molecule from its degradation products.

\section{Preparation of analgesic mixture samples}

Butorphanol tartrate injection and ropivacaine hydrochloride injection mixed together in a laminar airflow hood were added to commercial $100 \mathrm{~mL}$ polyolefin bags containing $0.9 \%$ sodium hydrochloride to produce solutions containing approximately $5 \mathrm{mg}$ butorphanol tartrate and 100 or $200 \mathrm{mg}$ ropivacaine hydrochloride. The butorphanol-ropivacaine admixture was filled in triplicate, protected from light and stored at $4^{\circ} \mathrm{C}$ and $25^{\circ} \mathrm{C}$ during a 15 -day study period. These doses assayed in the study were chosen, taking into consideration those more frequently used for postoperative pain via PCEA.

\section{Stability study of the analgesic mixtures}

A $2 \mathrm{~mL}$ sample was removed from each admixture immediately after preparation and after 8, 24, 48, 72, 120, 168, 240 and $360 \mathrm{~h}$. At each time point the solutions were examined for the development of colour, cloudiness, precipitation and gas production. Moreover, variations in the $\mathrm{pH}$ of the binary mixtures were also measured at 0 and 15 days using a $\mathrm{pH}$ meter. All samples were then frozen at $-20^{\circ} \mathrm{C}$ until analysis. Samples were allowed to reach room temperature and diluted threefold in purified water before injection into a HPLC system. Each sample was assayed in triplicate by HPLC.

\section{Analysis of data}

The starting concentration of both drugs was designated as $100.0 \%$; all subsequent concentrations were expressed as a percentage of the starting concentration. The drug was defined as stable if more than $90 \%$ of the starting concentration was retained. $^{15}$

Table 1 Validation of HPLC method

\begin{tabular}{|c|c|c|c|c|}
\hline \multirow[b]{2}{*}{ Compound } & \multirow[b]{2}{*}{$\begin{array}{l}\text { Concentration } \\
\text { tested (mg/L) }\end{array}$} & \multirow[b]{2}{*}{$\begin{array}{l}\text { Recovery } \\
(\%)\end{array}$} & \multicolumn{2}{|c|}{ Precision RSD (\%) } \\
\hline & & & Intra-day & $\begin{array}{l}\text { Inter-day } \\
\text { (5 days) }\end{array}$ \\
\hline Butorphanol tartrate & $\begin{array}{r}5.0 \\
15.0 \\
50.0\end{array}$ & $\begin{array}{r}100.2 \\
98.5 \\
99.7\end{array}$ & $\begin{array}{l}1.3 \\
0.7 \\
1.2\end{array}$ & $\begin{array}{l}2.4 \\
1.1 \\
1.6\end{array}$ \\
\hline Ropivacaine hydrochloride & $\begin{array}{r}200.0 \\
800.0 \\
1200.0\end{array}$ & $\begin{array}{r}100.3 \\
98.7 \\
99.6\end{array}$ & $\begin{array}{l}0.9 \\
0.5 \\
1.0\end{array}$ & $\begin{array}{l}1.2 \\
2.1 \\
1.5\end{array}$ \\
\hline
\end{tabular}




\section{RESULTS}

\section{Validation of the HPLC method}

Table 1 shows the results obtained for the accuracy, intra-day and inter-day RSD. The intra- and inter-day RSD\% were below $2.5 \%$ for both drugs, with the recoveries obtained also being close to $100 \%$. There was a good linear relationship between detector response and concentrations, with a correlation coefficient $(r)$ better than 0.999 for both drugs. The degradation study results showed that the decomposition products were baseline separated from analytes and none would interfere with the quantification of butorphanol tartrate and ropivacaine hydrochloride (figure 2).

\section{Stability of the infusions}

No colour change, precipitation, turbidity or gas production was observed in the admixtures in polyolefin bags. Tables 2 and 3 show the percentages of the dose of butorphanol tartrate and ropivacaine hydrochloride remaining in the admixtures when stored in polyolefin bags over a period of 15 days at $4^{\circ} \mathrm{C}$ and $25^{\circ} \mathrm{C}$. After $360 \mathrm{~h}$ of storage, the percentages of butorphanol and ropivacaine remaining in the drug mixtures were higher than $97 \%$ at both temperatures. Over the study period the $\mathrm{pH}$ value was close to 5 and changes were within 0.1 units of the initial $\mathrm{pH}$ for all drug mixtures.

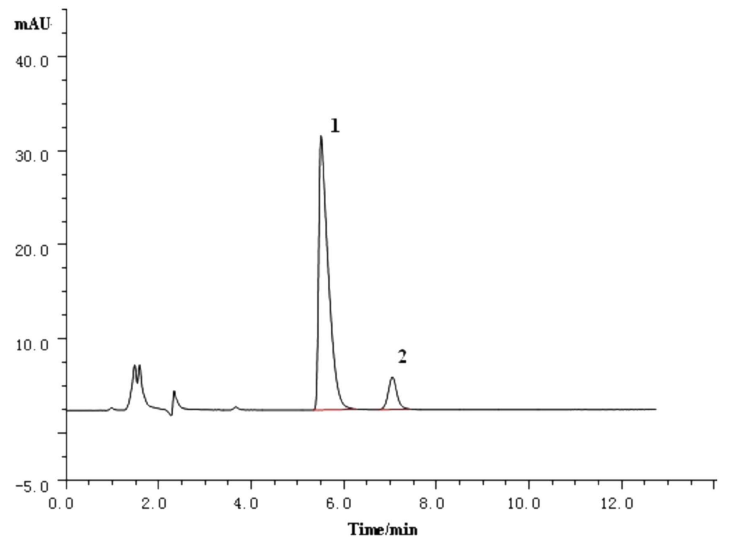

A

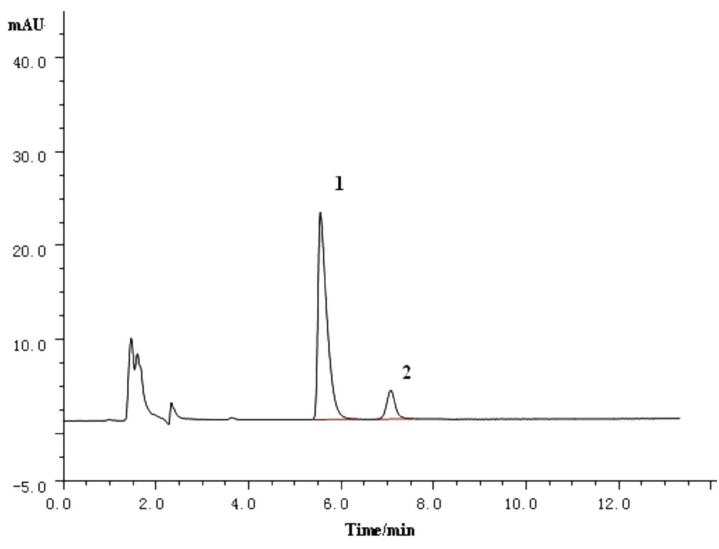

C

\section{DISCUSSION}

Multimodal analgesia is currently recommended as an effective analgesia for moderate to severe postoperative pain control, which is achieved by combining different analgesics such as opioids, non-steroidal anti-inflammatory drugs and local anaesthetics in order to minimise individual doses and to reduce unwanted side effects. ${ }^{2} 16$ However, when combinations of drugs are administered via PCEA infusion, drug incompatibility or loss of stability can occur. Previously, the physical compatibility and stability of butorphanol tartrate and ropivacaine alone or combined with other drugs in solution has been studied. Butorphanol tartrate was found to be stable for at least 1 week in $0.9 \%$ sodium chloride injection. ${ }^{17}$ The combination of butorphanol tartrate with other drugs in solution has shown variable results. It is stable when combined with droperidol but unstable with lornoxicam in $0.9 \%$ sodium chloride injection. ${ }^{18}{ }^{19}$ Ropivacaine has been shown to remain stable in infusion solution when combined with morphine, ${ }^{20}$ fentanyl, ${ }^{20}$ sufentanil, ${ }^{21-23}$ tramadol, $^{23}$ methylprednisolone acetate ${ }^{24}$ or diamorphine ${ }^{25}$ under normal conditions. Unfortunately, no published information is available on the compatibility and stability of butorphanol in combination with ropivacaine in PCEA solution. The aim of this study was therefore to fulfil this lack of information.

In this stability study the concentrations of butorphanol tartrate and ropivacaine hydrochloride chosen reflect the use of

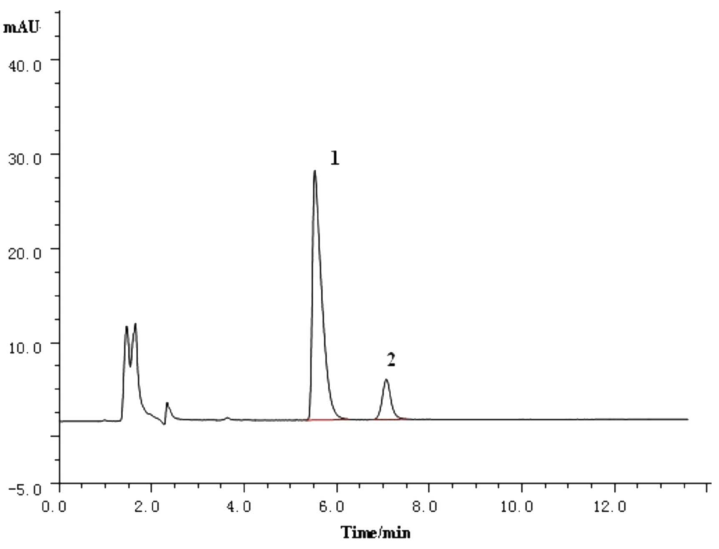

B

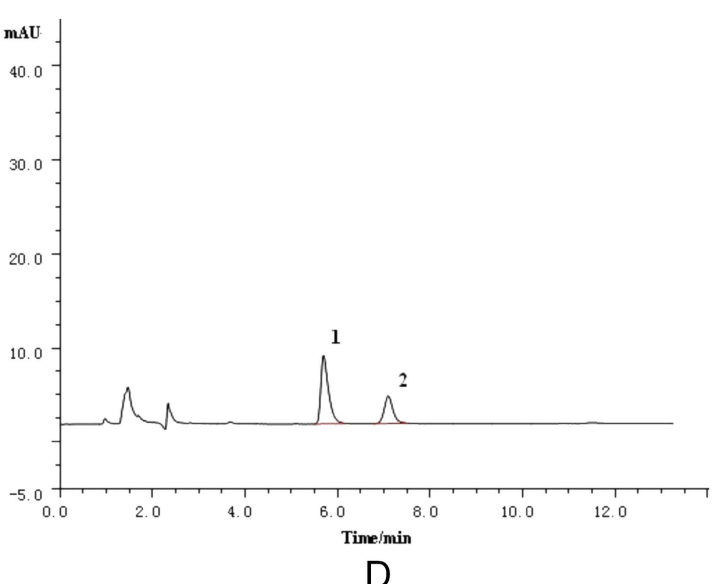

$\mathrm{D}$

Figure 2 Chromatograms of butorphanol tartrate $0.015 \mathrm{mg} / \mathrm{mL}$ and ropivacaine hydrochloride $0.8 \mathrm{mg} / \mathrm{mL}$ admixtures that were freshly prepared (A), exposed to $0.1 \mathrm{M}$ hydrochloric acid at $60^{\circ} \mathrm{C}$ for $5 \mathrm{hs}(\mathrm{B})$, exposed to $0.1 \mathrm{M}$ sodium hydroxide at $60^{\circ} \mathrm{C}$ for $5 \mathrm{~h}$ (C), and exposed to $3 \%$ hydrogen peroxide at $60^{\circ} \mathrm{C}$ for $5 \mathrm{~h}$ (D). Retention times were $5.6 \mathrm{~min}$ for ropivacaine hydrochloride (peak 1) and 7.1 min for butorphanol tartrate (peak 2). The other peaks were for degradation products. 
Table 2 Drug concentrations (mean $\pm S D(\%) ; n=3$ ) of butorphanol tartrate $(50 \mu \mathrm{g} / \mathrm{mL})$ and ropivacaine hydrochloride $(1 \mathrm{mg} / \mathrm{mL})$ in polyolefin bags at different storage conditions

\begin{tabular}{lccccc}
\hline & \multicolumn{2}{l}{ Solution stored at $4^{\circ} \mathrm{C}$} & & \multicolumn{2}{c}{ Solution stored at $25^{\circ} \mathrm{C}$} \\
\cline { 2 - 3 } Time (h) & Butorphanol & Ropivacaine & & Butorphanol & Ropivacaine \\
\hline 0 & 100.0 & 100.0 & & 100.0 & 100.0 \\
8 & $98.7 \pm 1.7$ & $101.1 \pm 0.1$ & & $98.7 \pm 0.5$ & $99.1 \pm 1.8$ \\
24 & $100.2 \pm 1.1$ & $102.5 \pm 1.3$ & & $98.3 \pm 1.2$ & $100.4 \pm 0.5$ \\
48 & $99.2 \pm 0.3$ & $99.8 \pm 0.7$ & & $102.2 \pm 2.1$ & $97.7 \pm 2.4$ \\
72 & $100.6 \pm 0.4$ & $102.1 \pm 1.6$ & & $101.8 \pm 0.9$ & $98.3 \pm 0.2$ \\
120 & $100.9 \pm 1.0$ & $97.5 \pm 2.2$ & & $100.3 \pm 2.0$ & $102.2 \pm 0.3$ \\
168 & $101.3 \pm 1.3$ & $100.4 \pm 0.7$ & & $99.9 \pm 1.1$ & $99.2 \pm 1.9$ \\
240 & $99.6 \pm 0.1$ & $101.2 \pm 1.0$ & & $100.4 \pm 0.2$ & $98.9 \pm 0.6$ \\
360 & $99.8 \pm 1.5$ & $102.1 \pm 0.9$ & & $98.5 \pm 0.7$ & $100.3 \pm 0.5$ \\
\hline
\end{tabular}

the combinations by specialist analgesic treatment teams, expert consensus $^{26}$ and clinical research ${ }^{9-13}$ in order to ensure that the results will have clinical utility. Administration of butorphanol in combination with ropivacaine via PCEA has been shown to improve postoperative pain with no serious side effects after surgery. ${ }^{9-13}$ However, the elimination half-life of butorphanol is nearly $18 \mathrm{~h}$ but, in patients with renal or hepatic impairment, it is approximately doubled or tripled. Due to the pharmacokinetic data, it is not recommended for the treatment of postoperative pain over a long period. In addition, the dosage should be adjusted and drug monitoring should be carried out if treatment is given to older patients or those with excretion problems.

When mixing drugs taken from ampoules of sterile solutions there is also the potential issue of bacterial contamination. We have examined the physicochemical stability without taking microbial contamination into consideration. In clinical practice it is necessary to follow Chapter 797 of the USP/NF ${ }^{27}$ In this regulation the preparation belongs to low-risk compounding sterile products. ${ }^{28}$ In order to ensure its safety, the preparation should not be used for more than $48 \mathrm{~h}$ after the date at room temperature or 14 days at refrigerated temperatures on the basis of USP specifications.

The results of our stability studies show that binary mixtures of butorphanol tartrate and ropivacaine hydrochloride in $0.9 \%$ sodium chloride injection are stable for at least 15 days when

Table 3 Drug concentrations (mean \pm SD (\%); $n=3$ ) of butorphanol tartrate $(50 \mu \mathrm{g} / \mathrm{mL})$ and ropivacaine hydrochloride $(2 \mathrm{mg} / \mathrm{mL})$ in polyolefin bags at different storage conditions

\begin{tabular}{lccccc}
\hline & \multicolumn{2}{l}{ Solution stored at $4^{\circ} \mathrm{C}$} & & \multicolumn{2}{c}{ Solution stored at $25^{\circ} \mathrm{C}$} \\
\cline { 2 - 3 } \cline { 6 - 6 } Time (h) & Butorphanol & Ropivacaine & & Butorphanol & Ropivacaine \\
\hline 0 & 100.0 & 100.0 & & 100.0 & 100.0 \\
8 & $100.1 \pm 0.5$ & $100.9 \pm 0.2$ & & $100.6 \pm 0.7$ & $100.7 \pm 0.6$ \\
24 & $100.9 \pm 2.0$ & $99.9 \pm 1.6$ & $99.7 \pm 1.1$ & $99.6 \pm 0.2$ \\
48 & $101.8 \pm 1.0$ & $100.0 \pm 0.5$ & & $101.1 \pm 0.9$ & $102.5 \pm 1.3$ \\
72 & $102.1 \pm 1.9$ & $99.3 \pm 1.0$ & & $102.6 \pm 0.8$ & $101.4 \pm 2.1$ \\
120 & $99.5 \pm 0.2$ & $99.6 \pm 1.2$ & & $99.4 \pm 0.7$ & $99.7 \pm 1.6$ \\
168 & $100.5 \pm 0.8$ & $100.2 \pm 0.8$ & & $98.5 \pm 1.3$ & $101.0 \pm 1.4$ \\
240 & $101.0 \pm 1.3$ & $101.5 \pm 0.3$ & & $100.3 \pm 1.1$ & $99.6 \pm 0.8$ \\
360 & $99.2 \pm 0.4$ & $100.1 \pm 1.1$ & $97.7 \pm 0.5$ & $101.8 \pm 0.9$ \\
\hline
\end{tabular}

stored in polyolefin bags at $4^{\circ} \mathrm{C}$ and $25^{\circ} \mathrm{C}$ and protected from light. Moreover, there were no significant differences between steady storage at room temperature and in the refrigerator. We therefore conclude that this solution can be safely prepared and stored out of light for up to 14 days by licensed Central Intravenous Additive services.

\section{CONCLUSION}

A new and validated analytical HPLC method for the simultaneous determination of butorphanol tartrate and ropivacaine hydrochloride in analgesic mixture samples used in PCEA has been successfully developed. The method was successfully used to study the stability of the binary mixture of butorphanol and ropivacaine at the usual concentration levels used in clinical practice. The results show that the mixture of butorphanol $(50 \mu \mathrm{g} / \mathrm{mL})$ and ropivacaine $(1-2 \mathrm{mg} / \mathrm{mL})$ prepared in $0.9 \%$ sodium chloride injections and stored at ambient or refrigerated storage conditions for $360 \mathrm{~h}$ is compatible and stable.

\section{Key messages}

\section{What is already known on this subject}

Butorphanol combined with ropivacaine patient-controlled epidural analgesia regimen is useful for successful postoperative analgesia and allows a balance of pain control, proper sedation and fewer side effects.

\section{What this study adds}

The epidural drug solution can be safely prepared by the pharmacist and can be stored in a refrigerator for up to 14 days at $4^{\circ} \mathrm{C}$.

Contributors FC and PL conceived and designed the experiments. FC, PL, BZ and JY performed the experiments. BF and JY analysed the data. $\mathrm{PL}, \mathrm{BZ}$ and $\mathrm{BF}$ contributed reagents/materials/analysis tools. FC, PL and BZ wrote the paper.

Funding This work was supported by Hubei Education Department Science \& Technology Foundation of China (grant number: D20122108).

\section{Competing interests None.}

Provenance and peer review Not commissioned; externally peer reviewed.

\section{REFERENCES}

1 Piekarski M, Jelińska A, Szymczak K. Development and validation of an HPLC method to determine the stability of fentanyl citrate and bupivacaine hydrochloride mixtures in infusion solutions. Eur J Hosp Pharm Sci Pract 2012;19:447-51.

2 Jin F, Chung F. Multi-modal analgesia for postoperative pain control. J Clin Anesth 2001;13:524-39

3 Wang LZ, Chang XY, Liu $X$, et al. Comparison of bupivacaine, ropivacaine and levobupivacaine with sufentanil for patient-controlled epidural analgesia during labor: a randomized clinical trial. Chin Med J 2010;123:178-83.

4 Sellon DC, Monroe VL, Roberts MC, et al. Pharmacokinetics and adverse effects of butorphanol administered by single intravenous injection or continuous intravenous infusion in horses. Am J Vet Res 2001;62:183-9.

5 Shrestha CK, Sharma KR, Shrestha RR. Comparative study of epidural administration of $10 \mathrm{ml}$ of $0.1 \%$ bupivacaine with $2 \mathrm{mg}$ butorphanol and $10 \mathrm{ml}$ of $0.25 \%$ plain bupivacaine for analgesia during labor. J Nepal Med Assoc 2007;46:1-6.

6 Wermeling DP, Foster TS, Farrington EA, et al. Patient-controlled analgesia using butorphanol for postoperative pain relief: an open-label study. Acute Care 1988;12 (Suppl 1):31-9.

7 Reedy ME, Morris LE, Brown DL, et al. Double-blind comparison of butorphanol and morphine in patient-controlled analgesia. Acute Care 1988;12(Suppl 1):40-6.

8 Markham A, Faulds D. Ropivacaine. A review of its pharmacology and therapeutic use in regional anaesthesia. Drugs 1996;52:429-49.

9 Ji JN, Kim YH, Shin YS. The effect of epidural butorphanol for analgesia after cesarean section. Korean J Anesthesiol 2003;45:205-9. 
$10 \mathrm{Kim} \mathrm{DH}$. The optimal concentration of ropivacaine in combination with butorphanol $50 \mathrm{microgram} / \mathrm{ml}$ for patient-controlled epidural analgesia. Korean J Anesthesiol 2002;43:749-54.

$11 \mathrm{Kim}$ DH. Effective continuous infusion and bolus doses for patient-controlled epidural analgesia using ropivacaine. J Korean Pain Soc 2002;15:75-9.

12 Zhou JM, Li LW, Zou DQ, et al. Effect of butrophanol and tramadol combined with ropivacaine on PCEA after cesarean. Chin J Mod Med 2010;20:3020-2.

13 Zeng $\mathrm{CH}$, Wu SY, Huang JW, et al. The efficacy of ropivacaine combined with butorphanol on patient with postoperative controlled epidural analgesia. Hebei Med 2012;18:452-5.

14 Gikic M, Di Paolo ER, Pannatier A, et al. Evaluation of physicochemical incompatibilities during parenteral drug administration in a paediatric intensive care unit. Pharm World Sci 2000;22:88-91.

15 Rockville MD. Guideline for submitting documentation for the stability of human drugs and biologics. Rockville, MD: Food and Drug Administration, 1987.

16 Skinner HB. Multimodal acute pain management. Am J Orthop (Belle Mead NJ) 2004;33:5-9.

17 Chen FC, Fang BX, Li P, et al. Study on the stability of butorphanol tartrate injection in 0.9\% sodium chloride injection. Chin Pharm 2012;15:1618-20.

18 Chen FC, Fang BX, Li P, et al. Compatibility of butorphanol and droperidol in $0.9 \%$ sodium chloride injection. Am J Health-Syst Pharm 2013;70:515-19.

19 Fang BX, Zhu J, Chen FC, et al. Stability of butorphanol tartrate injection with lornoxicam injection in patient controlled analgesia pump. Cent South Pharm 2013;11:732-4.
20 Svedberg KO, Chem E, McKenziet J, et al. Compatibility of ropivacaina with morphine, sufentanil, fentanyl, or clonidine. J Clin Pharm Ther 2002;27:39-45.

21 Brodner G, Mertes N, Van Aken $\mathrm{H}$, et al. What concentration of sufentanil should be combined with ropivacaine $0.2 \% \mathrm{wt} / \mathrm{vol}$ for postoperative patient controlled epidural analgesia? Anesth Analg 2000;90:649-57.

22 Brodner $\mathrm{G}$, Ermert T, Van Aken $\mathrm{H}$, et al. Stability of a sufentanil-ropivacaine mixture in a glass and a PVC reservoir. Eur J Anaesthesiol 2002;19:295-7.

23 Salmerón-García A, Navas N, Martín A, et al. Determination of tramadol, metamizole, ropivacaine, and bupivacaine in analgesic mixture samples by HPLC with DAD detection. J Chromatogr Sci 2009;47:231-7.

24 Robustelli della Cuna FS, Mella M, Magistrali G, et al. Stability and compatibility of methylprednisolone acetate and ropivacaine hydrochloride in polypropylene syringes for epidural administration. Am J Health-Syst Pharm 2001;58:1753-6.

25 Sánchez del Aguila MJ, Jones MF, Vohra A. Premixed solutions of diamorphine in ropivacaine for epidural anaesthesia: a study on their long-term stability. $\mathrm{Br} J$ Anaesth 2003;90:179-82.

26 Huang YG, Huang WQ, Li G, et al. Analgesic expert consensus of butorphanol tartrate. J Clin Anesthesiol 2011;27:1028-31.

27 Kastango ES, Bradshaw BD. USP chapter 797: Establishing a practice standard for compounding sterile preparations in pharmacy. Am J Health-Syst Pharm 2004;61:1928-38.

28 Trissel LA. The new national standard for sterile preparation. Hosp Pharm 2004:39:900-4. 